\title{
A New Method for Live Line Measurement of Zero Sequence Parameters of T-Type Transmission Lines with Mutual Inductance
}

\author{
Liu Jiaxin \\ State Grid Liaoning Electrical Power Research Institute \\ Shenyang, China \\ liujxldk@163.com
}

\begin{abstract}
A new method for live line measurement of zerosequence parameters of T-type transmission lines with mutual inductance is proposed. Firstly the T-type lines and multi-branch lines are equivalent to parallel transmission lines with mutual inductance, and then the live line measurement for parameters of T-type transmission lines is achieved by using integral equation. Measuring principle of live line measurement, noise processing of data sampling and error correction and mathematical model of approximate calculation are explained in detail. This method uses global positioning system as the synchronous time tag of data acquisitions at different substations. The digital simulation results prove that the new method can meet the needs of live line measurement of inductance parameters.
\end{abstract}

Keywords-global positioning system; T-type transmission line; zero sequence impedance; live line measurement

\section{INTRODUCTION}

With the grow of number of power plant (substation) outlet lines, T-type transmission lines are getting more and more. Zero sequence impedance of T-type transmission lines could impact its fault state, especially the level of zero sequence current, and would greatly influence the protection of zero sequence current. Since the zero sequence impedance of T-type transmission lines is affected by many factors, theoretical calculation value [1] is unable to meet the precision requirement of relay protection setting calculation, and the conventional measuring methods [2-4] are difficult to implement. Therefore, the regulation of relay protection setting points out that, zero sequence impedance and other parameters of overhead lines and cables which greatly affect relay protection should adopt the measured value [5].

With the gradual rise of live line measurement to zero sequence parameters of transmission lines with mutual inductance, the method for live line measurement to parameters of transmission lines based on integral equation solves the problem that traditional methods could not obtain the zero sequence parameter of transmission lines with mutual inductance accurately. For T-type lines and multi-terminal lines, due to the shunt of incremental current, the inherent algorithm could not be applied directly and the measurement has to be proceeded in case of part outage.

This paper presents a model which makes T-type lines and multi-terminal lines equivalent to parallel transmission lines with mutual inductance and a new method to achieve live line measurement to parameters of T-type transmission lines based on integral equation. Using GPS [6-7], one can develop live line measurement device of zero sequence impedance parameter of T-type transmission lines to achieve a accurate measurement of zero sequence impedance parameter of operating T-type transmission lines.

\section{PRINCIPLE}

The model of a double parallel line is shown in Fig. 1, where Line 2 is a T-type line with two branch lines L1 and L2.

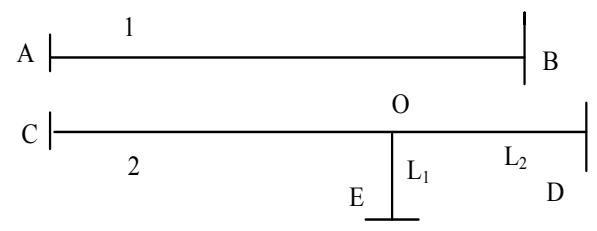

Figure 1. Diagram of a multi-terminal transmission line.

In Fig. 1, there is zero sequence mutual inductance between Line 1 and Line 2 . Since the voltage and current signal of point $\mathrm{O}$ is difficult to obtain in practical engineering, the traditional outage measuring method is generally limited by actual situation. The live line measurement needs to power off Line 2, L1, and L2, and then proceed by applying zero sequence interference source in each branch line one by one or shortly disconnecting a branch line by breaker. But neither traditional nor live line measuring method is unable to measure the zero sequence self-impedance of segment $\mathrm{CO}$, DO and EO accurately, not to mention the mutual inductance between branch lines.

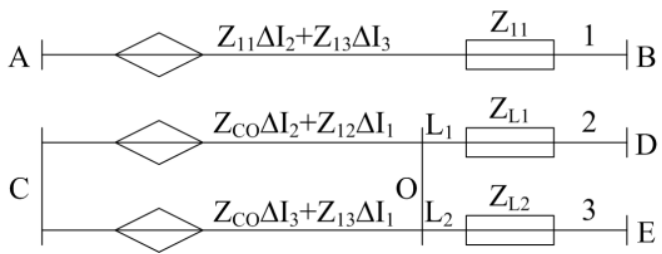

Figure 2. Controlled model of T-type transmission line.

As shown in Fig. 1, the voltage of segment $\mathrm{CO}$ in Line 2 is controlled by branch current $I_{\mathrm{L} 1}$ and $I_{\mathrm{L} 2}$, considering Line 2 and its branch line individually. If it is separated into two parallel lines $\mathrm{CD}$ and $\mathrm{CE}$ by branch point $\mathrm{O}$, one 
can obtain a controlled source model as shown in Fig. 2, by using a controlled voltage source to express the voltage produced by branch current of segment $\mathrm{CO}$ and mutual inductance between each lines.

In Fig. 2, $Z_{\mathrm{CO}}$ is the zero sequence self-impedance of segment $\mathrm{CO}, Z_{12}$ is the zero sequence mutual inductance between Line 1 and Line 2 , and $Z_{13}$ is the zero sequence mutual inductance between Line 1 and Line 3 . Since branch lines L1 and L2 are generally with large angle and rarely in the same line corridor after branched, the mutual inductance between these two branch lines is generally low enough to be ignored. According to the line model in Fig. 2, one can obtain zero sequence current increment equation:

$$
\left[\begin{array}{l}
\Delta U_{\mathrm{AB}} \\
\Delta U_{\mathrm{CD}} \\
\Delta U_{\mathrm{CE}}
\end{array}\right]=\left[\begin{array}{ccc}
Z_{11} & Z_{12} & Z_{13} \\
Z_{12} & Z_{\mathrm{CO}}+Z_{\mathrm{L} 1} & Z_{\mathrm{CO}} \\
Z_{13} & Z_{\mathrm{CO}} & Z_{\mathrm{CO}}+Z_{\mathrm{L} 2}
\end{array}\right]\left[\begin{array}{c}
\Delta I_{1} \\
\Delta I_{2} \\
\Delta I_{3}
\end{array}\right],(1)
$$

where $Z_{11}, Z_{\mathrm{L} 1}$, and $Z_{\mathrm{L} 2}$ are the zero sequence selfimpedance of Line 1, branch segment DO and EO, respectively, $\Delta I_{i}$ and $\Delta U_{i j}$ are the zero sequence current and zero sequence voltage increment vector of each measured lines, respectively. Further, a three parallel line in general case similar to the structure in Fig. 2 is shown in Fig. 3.

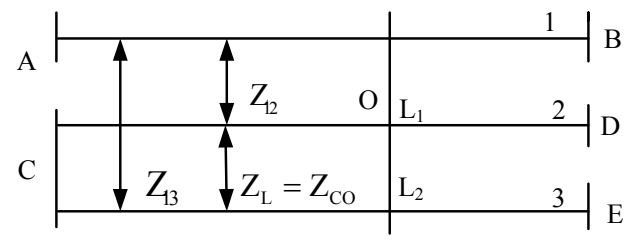

Figure 3. Mutual inductance model of transmission line.

The zero sequence current increment equation is:

$$
\begin{aligned}
& {\left[\begin{array}{l}
\Delta U_{\mathrm{AB}} \\
\Delta U_{\mathrm{CD}} \\
\Delta U_{\mathrm{CE}}
\end{array}\right]=\left[\begin{array}{lll}
Z_{11} & Z_{12} & Z_{13} \\
Z_{12} & Z_{22} & Z_{23} \\
Z_{13} & Z_{23} & Z_{33}
\end{array}\right]\left[\begin{array}{c}
\Delta I_{1} \\
\Delta I_{2} \\
\Delta I_{3}
\end{array}\right],} \\
& \left\{\begin{array}{l}
\left(u_{\mathrm{AB}}(k+1)+u_{\mathrm{AB}}(k)\right) T_{s} \\
2
\end{array}=R_{11} \frac{\left(i_{1}(k+1)+i_{1}(k)\right) T_{s}}{2}+L_{11}\left(i_{1}(k+1)-\right.\right. \\
& \frac{\left(u_{\mathrm{CE}}(k+1)+u_{\mathrm{CE}}(k)\right) T_{s}}{2}=R_{13} \frac{\left(i_{1}(k+1)+i_{1}(k)\right) T_{s}}{2}+L_{13}\left(i_{1}(k+1)-{ }^{2}\right. \\
& \text { where } i_{i}(k+1) \text { and } i_{i}(k) \text { are the sample values of zero } \\
& \text { sequence current at two adjacent sampling times after } \\
& \text { injection of zero sequence current; } u_{i j}(k+1) \text { and } u_{i j}(k) \\
& \text { are the sample values of zero sequence voltage at two } \\
& \text { adjacent sampling times after injection of zero sequence } \\
& \text { current; } T_{s} \text { is the sampling period. } \\
& \text { The error measurement steady-state data of caused by } \\
& \text { replacing current integral by trapezoid method can be } \\
& \text { corrected by correction coefficient }[10] \text {. The current signal } \\
& \text { can be expressed by sine function: } i=I_{m} \text { sin }(\omega \mathrm{t}+\varphi) \text {, }
\end{aligned}
$$

where $Z_{22}=Z_{\mathrm{CO}}+Z_{\mathrm{L} 1}$ and $Z_{33}=Z_{\mathrm{CO}}+Z_{\mathrm{L} 2}$ are zero sequence self-impedance of Line $C D$ and $C E$, respectively.

Compared (1) with (2), one can see that the two equations are very close. Regard the line as a passive six terminal network with the same voltage and current between the correspoding terminals of Fig. 2 and Fig. 3, (1) is equal to (2) and one can obtain $Z_{23}=Z_{\mathrm{CO}}$. In other words, if the zero sequence mutual inductance between branch lines L1 and L2 in Fig. 1 is not taken into account, the zero sequence mutual inductance between lines CD and $\mathrm{CE}$ in the controlled source model is in fact the zero sequence self-impedance of segment $\mathrm{CO}$.

Changing T-type line into parallel multi-line for calculating, on can obtain not only zero sequence selfimpedance with mutual inductance between each line (including branches), but also the zero sequence selfinductance of each line. For example, there is $Z_{\mathrm{CO}}=Z_{23}$, $Z_{\mathrm{L} 1}=Z_{22}-Z_{\mathrm{CO}}$, and $Z_{\mathrm{L} 2}=Z_{33}-Z_{\mathrm{CO}}$. During actual measurement, one can regard the voltage and current signal of line first segment with branch as one line accessed to the measuring device, or as two lines processed by software. According Fig. 3, the differential equations of T-type transmission lines are as follows:

$$
\left[\begin{array}{l}
u_{\mathrm{AB}} \\
u_{\mathrm{CD}} \\
u_{\mathrm{CE}}
\end{array}\right]=\left[\begin{array}{llllll}
R_{11} & L_{11} & R_{12} & L_{12} & R_{13} & L_{13} \\
R_{12} & L_{12} & R_{22} & L_{22} & R_{23} & L_{23} \\
R_{13} & L_{13} & R_{23} & L_{23} & R_{33} & L_{33}
\end{array}\right]\left[\begin{array}{c}
i_{1} \\
\frac{\mathrm{d} i_{1}}{\mathrm{~d} t} \\
i_{2} \\
\frac{\mathrm{d} i_{2}}{\mathrm{~d} t} \\
i_{3} \\
\frac{\mathrm{d} i_{3}}{\mathrm{~d} t}
\end{array}\right]
$$

Using integral method [8-9] on both sides of (3). If $T_{s}=t_{k+1}-t_{k}$, where $k$ is the number of sampling points, The integral values can be approximated using trapezoidal method by software programming and can be discreted as:

$$
\left\{\begin{array}{l}
\frac{\left(u_{\mathrm{AB}}(k+1)+u_{\mathrm{AB}}(k)\right) T_{s}}{2}=R_{11} \frac{\left(i_{1}(k+1)+i_{1}(k)\right) T_{s}}{2}+L_{11}\left(i_{1}(k+1)-i_{1}(k)\right)+\mathrm{L}+R_{13} \frac{\left(i_{3}(k+1)+i_{3}(k)\right) T_{s}}{2}+L_{13}\left(i_{3}(k+1)-i_{3}(k)\right) \\
\mathrm{L} \\
\frac{\left(u_{\mathrm{CE}}(k+1)+u_{\mathrm{CE}}(k)\right) T_{s}}{2}=R_{13} \frac{\left(i_{1}(k+1)+i_{1}(k)\right) T_{s}}{2}+L_{13}\left(i_{1}(k+1)-i_{1}(k)\right)+\mathrm{L}+R_{33} \frac{\left(i_{3}(k+1)+i_{3}(k)\right) T_{s}}{2}+L_{33}\left(i_{3}(k+1)-i_{3}(k)\right)
\end{array}\right.
$$

where $I_{m}, \omega$, and $\varphi$ are amplitude, angular frequency and initial phase, respectively.

The current integral of point $k$ is:

$$
\begin{aligned}
\int_{k}^{k+1} i(\mathrm{t}) \mathrm{dt} & =\int_{k}^{k+1} I_{m} \sin (\omega \mathrm{t}+\varphi) \mathrm{dt} \\
& =-\frac{I_{m}}{\omega}\left[\cos \left((k+1) \frac{2 \pi}{N}+\varphi\right)-\cos \left(k \frac{2 \pi}{N}+\varphi\right)\right],(5) \\
& =\frac{2 I_{m}}{\omega} \sin \left((2 k+1) \frac{\pi}{N}+\varphi\right) \sin \frac{\pi}{N}
\end{aligned}
$$


Using trapezoidal method, the integral of point $k$ can be calculated as:

$$
\begin{aligned}
\frac{i_{k+1}+i_{k}}{2} T_{s} & =\frac{I_{m}}{2}\left[\sin \left((k+1) \frac{2 \pi}{N}+\varphi\right)+\sin \left(k \frac{2 \pi}{N}+\varphi\right)\right] \frac{2 \pi}{\omega N}, \\
& =\frac{2 \pi I_{m}}{\omega N} \sin \left((2 k+1) \frac{\pi}{N}+\varphi\right) \cos \frac{\pi}{N}
\end{aligned}
$$

The correction coefficient of current integral item is:

$$
a_{i}=\frac{\frac{i_{k+1}+i_{k}}{2} T_{s}}{\int_{k}^{k+1} i(\mathrm{t}) \mathrm{dt}}=\frac{\frac{\pi}{N} \cos \frac{\pi}{N}}{\sin \frac{\pi}{N}},
$$

On the same principle, the correction coefficient of voltage integral item is the same as the one of current integral item. One can see that as long as the sampling points $N$ is certain, the correction coefficient is a constant value.

\section{PARAMETER MEASUREMENT}

\section{A. Live Line Measurement Method}

The operation modes of T-type transmission lines in live line measurement are shown in Tab. 1.

TABLE I. THE INDEPENDENT OPERATION CASES FOR LIVE LINE MEASUREMENT

\begin{tabular}{|c|l|l|l|l|}
\hline \multirow{2}{*}{$\begin{array}{c}\text { Operation } \\
\text { Case }\end{array}$} & \multicolumn{1}{|c|}{ Line 1 } & \multicolumn{1}{|c|}{ T-type lines } \\
\cline { 3 - 5 } & \multicolumn{1}{|c|}{ Branch line CO } & \multicolumn{1}{c|}{ Branch line $\boldsymbol{L}_{\boldsymbol{1}}$} & \multicolumn{1}{c|}{ Branch line L $_{2}$} \\
\hline 1 & $\begin{array}{l}\text { Single-phase tripping, } \\
\text { reclose in 0.5-1 s }\end{array}$ & Normal operation & Normal operation & Normal operation \\
\hline 2 & Normal operation & $\begin{array}{l}\text { Single-phase tripping, } \\
\text { reclose in 0.5-1 s }\end{array}$ & Normal operation & Normal operation \\
\hline 3 & Normal operation & Normal operation & $\begin{array}{l}\text { Single-phase tripping, } \\
\text { reclose in 0.5-1 s }\end{array}$ & Normal operation \\
\hline 4 & Normal operation & Normal operation & Normal operation & $\begin{array}{l}\text { Single-phase tripping, } \\
\text { reclose in } 0.5-1 \mathrm{~s}\end{array}$ \\
\hline
\end{tabular}

To produce incremental, one can apply zero sequence current which is high enough in a certain line or shortly $(0.5-1.0 \mathrm{~s})$ disconnect a certain line phase to produce a high zero sequence current by controlling relay protection device. This is a key technology of live line measurement. Since measurement is usually conducted in power plants and substations far away, there should be unified measuring time scale for incremental measurement and the synchronization of measured data. Using global positioning system (GPS) one can obtain benchmark with error less than $1 \mu \mathrm{s}$, which is another key technology of live line measurement.

\section{B. Integral equation solution}

For (4), measurement data are sampled according to any operation mode in Tab. 1. One can obtain three separate equations by taking the zero sequence voltage and zero sequence current sampling values corresponding to two adjacent sampling point $k$ and $k+1$; one can obtain another three separate equations by taking the zero sequence voltage and zero sequence current sampling values corresponding to another two adjacent sampling point $k+1$ and $k+2$; thus each separate measurement mode could obtain six separate equations; one can obtain six or more separate equations by sampling data using another two or more operation modes in Tab. 1; there are 12 separate equations at least, using which one can solve 12 unknown zero sequence parameters: $R_{i j}$ and $L_{i j}$, where $i$, $j=1,2,3$. Solving by the least square method, there is $\mathrm{Z}=\left(I^{T} I\right)^{-1} I^{T} U$, where $Z_{i j}=R_{i j}+h L_{i j}, h$ is the imaginary unit.
By the above analysis one can find out the zero sequence impedance with mutual inductance between each lines (including branches), and also the zero sequence impedance of each branch.

\section{Noise Processing}

Zero sequence current and zero sequence voltage can be measured by zero sequence current transformer and zero sequence voltage transformer, respectively. But the measured data contain some measurement noise, which would affect the parameter identification results [11-13].

Taking high order harmonic component and measurement noise of measured data into account, highorder sine function is used as a signal model and sample data are sine curve fitted. The result shows that the fitting of each parameter is very accurate under low measurement noise. Since the steady-state zero sequence current and zero sequence voltage are sine waves and frequency is known to be $50 \mathrm{~Hz}$, one can only determine amplitude and phase. Therefore one can firstly fit measured data into sine curves by software, and then discrete sample to the fitted curves, finally, calculate the test parameters by substituting sample values into algorithm .

\section{Measuring Steps}

The live line measurement method of zero sequence impedance parameters of T-type transmission lines includes the following steps: 
(1) Close the zero sequence protection device of related line. Disconnect any single-phase breaker of operating T-type line by relay protection device on the line to operate lack of phase and the zero sequence current for measuring is supplied by load current. After 0.5-1 s, big zero sequence current is supplied for live line measurement by recovering line normal operation using automatic reclosing device on T-type line. The operation modes of T-type transmission line in live line measurement is shown in Tab. 1.

(2) One can obtain a benchmark with error less than 1 $\mu$ s using timing function of GPS (global positioning system). By the Time synchronization of global positioning system, the zero sequence current instantaneous value of each line and zero sequence voltage instantaneous value at each line endpoint before and after the injection of zero sequence current are sampled simultaneously and saved into acquisition device in the form of a file.

(3) The data of each measuring point are summarized to center computer by network when measurement is completed. Center computer calculates the zero sequence impedance of T-type transmission line using integral equation method after receiving the sampling data of zero sequence current and zero sequence voltage of T-type transmission line.

\section{MATHEMATICAL SimUlation}

Mathematical Simulation is carried to verify the validity of live line measurement method proposed by this paper. The MATLAB simulation model is shown in Fig. 1. The zero sequence impedance parameters of simulated $\mathrm{T}$ type lines are shown in Tab. 2. The error can be expressed as:

$$
\text { Error }=\left|\frac{\text { Real value }- \text { simulation value }}{\text { Real value }}\right| \times 100 \%
$$

TABLE II. PARAMETERS OF MULTI-TERMINAL LINES

\begin{tabular}{|c|c|c|c|c|}
\hline Line & AB & CO & DO & EO \\
\hline Length $(\mathrm{km})$ & 30 & 20 & 30 & 20 \\
\hline $\begin{array}{c}\text { Zero sequence } \\
\text { self-resistance }(\Omega / \mathrm{km})\end{array}$ & 0.3864 & 0.3864 & 0.3864 & 0.3864 \\
\hline $\begin{array}{c}\text { Zero sequence } \\
\text { self-inductance }(\mathrm{mH} / \mathrm{km})\end{array}$ & 4.1264 & 4.1264 & 4.1264 & 4.1264 \\
\hline $\begin{array}{c}\text { Zero sequence } \\
\text { mutual impedance }(\Omega)\end{array}$ & $2+\mathrm{j} 6.28$ & - & - \\
\hline
\end{tabular}

TABLE III. RESULTS OF DIGITAL SIMULATION

\begin{tabular}{|c|c|c|c|}
\hline Line & Set Value $(\mathbf{\Omega})$ & $\begin{array}{c}\text { Simulated } \\
\text { Value }(\mathbf{\Omega})\end{array}$ & $\begin{array}{c}\text { Error } \\
(\mathbf{\%})\end{array}$ \\
\hline AB Self-impedance & $11.592+\mathrm{j} 38.8707$ & $11.712+\mathrm{j} 39.0012$ & 0.39 \\
\hline CO Self-impedance & $7.728+\mathrm{j} 25.9138$ & $7.783+\mathrm{j} 26.0011$ & 0.37 \\
\hline DO Self-impedance & $11.592+\mathrm{j} 38.8707$ & $11.621+\mathrm{j} 38.9001$ & 0.089 \\
\hline EO Self-impedance & $7.728+\mathrm{j} 25.9138$ & $7.790+\mathrm{j} 25.9721$ & 0.27 \\
\hline $\begin{array}{c}\text { Zero sequence } \\
\text { mutual impedance }\end{array}$ & $2+\mathrm{j} 6.28$ & $2.07+\mathrm{j} 6.30$ & 0.62 \\
\hline
\end{tabular}

The simulation calculation results are shown in Tab. 3 with a sampling rate of 80 points / cycle. As shown in Tab.
3, the live line measurement method proposed by this paper is with correct principle and results, which is valuable to engineering application.

\section{CONCLUSION}

This paper converts T-type transmission line equivalent to parallel mutual inductance lines, making traditional live line measurement method of the zero sequence impedance parameters of transmission lines can be used for T-type systems. Since the validity is verified by simulated calculation, it is possible for actual line measurement when conditions are ripe in the future. In addition to live line measurement of zero sequence parameters of T-type transmission lines, this method is also applicable to outage measurement of zero sequence parameters of T-type transmission lines.

\section{REFERENCES}

[1] K.C. Chen and K.M. Damrau, "Accuracy of Approximate Transmission Line Formulas for Overhead Wires," IEEE Trans on Electromagnetic Compatibility, vol. 31, Nov, 1989, pp. 396-397, doi: $10.1109 / 15.43635$.

[2] Z.Q. Hong, B.B.Zhang, Y. T. Jin, et al., "Study and Realization of Zero-sequence parameters Interference of Overhead Transmission Lines," High Voltage Apparatus, vol. 42, 2006, pp. 35-37.

[3] W.X. Lu, Research on Transmission Line Power Frequency Parameters. Beijing: North China Electric Power University, 2009.

[4] Z.J. Hu, C.X. Zhang, Y.P. Chen, et al., "Studying and Realization of Parameters Measurement Under Operation of Transmission Lines Based on GPS Technology," Proceedings of the EPSA. 2000, pp. 36-40.

[5] Z.J. Hu, A T-Connection Transformer Containing Live Line Measurement Method and Device of Zero Sequence Impedance Parameters: China Patent, 200710053527.0, 2008.

[6] N. Hu, G. Zheng, and Z.J. Hu, "Study of Live Line Measurement of Parameters of Transmission Lines with Mutual Inductance Based on Integral Equations," Relay, vol. 33, 2005, pp. 22-25.

[7] N. Hu, Z.J. Hu, G. Zheng, "Live Line Parameter Measurement of Transmission Lines with Mutual Inductance Based on GPS Technology and Integral Equation," IPower System Technology, vol. 29, 2005, pp. 76-80.

[8] C. Huang, Study of Live Line Measurement of Zero-Sequence Parameters of Overhead Transmission Lines. Nanjing: Nanjing University of Science and Technology, 2010.

[9] D.F. Zhang, Program Design and Typical Application of MATLAB. Beijing: Publishing House of Electronics Industry, 2009.

[10] W. Xu, Research on Parameter Measurement of Transmission Line and Harmonics Analysis System (The Part of parameter Measurement of Transmission Line). Wuhan: Wuhan University, 2004.

[11] W.L. Wang, F.Q. Li, and K.X. Tan, "Higher-Order Sine Fitting Algorithm for Dielectric Loss Measurement," Journal of Tsinghua University (Science and Technology), vol. 41, 2001, pp. 5-8.

[12] Y.F. Li, and J.J. Wu, "Method for Eliminating Voltage of Positive Sequence Impedance Interference Measurement of Overhead Transmission Lines," Northeast Electric Power Technology, vol. 30, 2009, pp. 47-49.

[13] J.Q. Guo, Z.J. Hu, J.X. Guo, et al.,"Study on Zero-Sequence Distributed Parameter Live Measurement of Transmission Lines with Mutual Inductance," High Voltage Apparatus, vol. 46, 2005, pp. 425-428. 